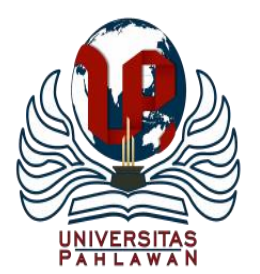

Jurnal Basicedu Volume 5 Nomor 1 Tahun 2021 Halaman 272-279

JURNALBASICEDU

Research \&Learningin Elementary Education

https://jbasic.org/index.php/basicedu

\title{
Peningkatan Kemampuan Membaca Pemahaman melalui Strategi Probing-Prompting bagi Anak Berkesulitan Belajar
}

\author{
Melly Nadya Afrianti ${ }^{1}$, Marlina Marlina ${ }^{2}$ \\ Universitas Negeri Padang, Indonesia ${ }^{1,2}$ \\ Email: mellynadya@gmail.com ${ }^{1}$, lina_muluk@ fip.unp.ac.id ${ }^{2}$
}

\begin{abstract}
Abstrak
Salah satu hambatan yang dihadapi anak berkesulitan belajar yaitu rendahnya tingkat pemahaman terhadap suatu bacaan. Permasalahan ini ditemukan di SDN 31 Kumpulan Banang yang mana anak berkesulitan belajar berumur 11 tahun memiliki tingkat pemahaman yang rendah. Penelitian ini bertujuan untuk membuktikan adanya pengaruh strategi probing-prompting dalam meningkatkan keterampilan membaca pemahaman literal anak berkesulitan belajar di SDN 31 Kumpulan Banang. Jenis penelitian yang dipakai adalah eksperimen dalam bentuk subjek tunggal Single Subject Research (SSR) dengan desain A-B-A yang terdiri dari tiga kondisi. Teknik pengumpulan data dalam penelitian ini menggunakan tes langsung lisan dan tulisan dengan menyuruh anak membaca teks cerita, menjawab lima pertanyaan kemudian menceritakan kembali teks cerita yang sudah dibaca dengan bahasa sendiri yang dilakukan sebelum dan sesudah diberikan intervensi serta pengumpulan datanya dilakukan melalui persentase. Data dikumpulkan melalui instrumen tes membaca pemahaman literal. Setelah data terkumpul, data dianalisis menggunakan teknik visual grafik. Hasil penelitian ini menyatakan bahwa strategi probing-prompting dapat meningkatkan keterampilan membaca pemahaman bagi anak berkesulitan belajar kelas V di SDN 31 Kumpulan Banang sesuai dengan analisis data dalam kondisi dan antar kondisi.
\end{abstract}

Kata kunci: strategi probing-prompting, keterampilan membaca pemahaman, anak berkesulitan belajar.

\section{Abstract}

One of the obstacles that children have with learning difficulties is the low level of understanding of a reading. This problem was found in SDN 31 Kumpulan Banang where 11 year old children with learning difficulties have a low level of understanding. The purpose of this study was to prove the effect of prompting-prompting strategies in improving literal comprehension reading skills of children with learning difficulties at SDN 31 Kumpulan Banang. The type of research used is an experiment in the form of a single subject Single Subject Research (SSR) with an A-B-A design. Baseline conditions (A1) consist of four meetings, intervention conditions (B) seven meetings and Baseline conditions (A2) six meetings. Data collection techniques in this study used direct oral and written tests by asking children to read the story text, answer five questions then retell the story text that had been read in their own language before and after the intervention was given and data collection was carried out through percentages. Data were collected through literal comprehension reading instruments. After the data was collected, the data were analyzed using visual graph techniques. The results of this study indicate that the probing-prompting strategy can improve reading comprehension skills for children with learning difficulties in grade V at SDN 31 Kumpulan Banang.

Keywords: probing-prompting strategy, reading comprehension skills, children with learning difficulties

Copyright (c) 2021 Melly Nadya Afrianti, Marlina Marlina

$\triangle$ Corresponding author :

Address : Pasar Bukit, Air Haji

Email : mellynadyaa@gmail.com

Phone : 083802007282

DOI : https://doi.org/10.31004/basicedu.v5i1.653

ISSN 2580-3735 (Media Cetak)

ISSN 2580-1147 (Media Online) 
273 Peningkatan Kemampuan Membaca Pemahaman Melalui Strategi Probing-Prompting bagi Anak Berkesulitan Belajar - Melly Nadya Afrianti, Marlina Marlina

DOI : https://doi.org/10.31004/basicedu.v5i1.653

\section{PENDAHULUAN}

Membaca sangat penting bagi semua orang, dengan membaca orang akan mendapatkan banyak informasi-informasi penting, salah satunya informasi tentang pendidikan (Abidin, 2012). Di dunia pendidikan membaca merupakan pokok utama dalam belajar, karena jika seseorang mengalami kesulitan dalam membaca maka akan membuat seseorang sulit juga dalam mengikuti pembelajaran apalagi saat guru memperintahkan murid untuk membaca secara bergantian, sehingga akan terlihat tidak adanya hubungan timbal balik guru dan siswa saat belajar (Khasanah \& Cahyani, 2016).

Membaca juga termasuk ke dalam proses fisik dan mental, dalam proses fisik membaca menyangkut ketajaman gerak mata, sedangkan dalam proses mental membaca menyangkut pahamnya seseorang terhadap bacaan yang dibaca (Marlina, 2015b). Orang dikatakan bisa membaca dengan baik jika dia bisa dengan jelas melihat huruf yang dibaca, menggerakkan mata dengan lincah, serta mampu dalam mengingat simbol seperti titik koma dalam bacaan. Selain mengingat simbol membaca juga bertujuan untuk memahami dan mengambil intisari dari bacaan yang ada dalam sebuah tulisan yang ditulis orang lain (Motallebzadeh, 2011).

Membaca juga memiliki banyak tingkatan salah satunya adalah membaca pemahaman literal. Membaca pemahaman literal termasuk ke dalam proses membaca yang memahami informasi yang terkandung dalam bacaan, jika dalam memahami informasi yang ada dalam cerita anak tidak bisa atau masih ragu-ragu maka bisa jadi salah satu pemicu anak sulit dalam belajar (Marlina, 2019). Kesulitan belajar merupakan satu dari banyak masalah dalam proses pendidikan terutama dalam belajar. Kesulitan belajar dapat dilihat langsung dari bagaimana proses belajar dan hasil yang didapati anak saat belajar maupun saat setelah anak belajar (Marlina, 2015a).

Berdasarkan hasil observasi yang dilakukan di SDN 31 Kumpulan Banang pada bulan MaretApril 2020 peneliti menemukan satu orang anak berkesulitan belajar yang mengalami kesulitan dalam membaca pemahaman khususnya dalam membaca pemahaman literal. Anak tersebut sudah bisa membaca tetapi anak tidak bisa memahami isi dari bacaan yang dibaca, anak tidak bisa mengulang ataupun menceritakan kembali isi bacaan yang dibaca, anak juga mengalami kesulitan dalam menjawab pertanyaan, anak sering tertinggal saat menjawab pertanyaan dan anak juga lebih banyak diam saat proses belajar.

Kesulitan dalam membaca pemahaman literal tentu memerlukan solusi apabila pendidik mencoba berbagai cara yang bervariasi dalam mengajarkan anak untuk memahami bacaan, karena kesulitan dalam memahami bacaan yang dialami anak selama ini tentu juga disebabkan oleh kurangnya kreativitas pendidik dalam mengajar (Abdullah, 2017). Pendidik selama ini hanya menjadi pusat utama dalam pembelajaran, pendidik menyampaikan materi pembelajaran secara langsung kepada anak dengan berbicara panjang lebar tanpa memberikan kesempatan banyak kepada anak untuk bertanya dan mengeluarkan pendapat, pendidik juga selalu mengutamakan anak-anak yang pintar saja 
274 Peningkatan Kemampuan Membaca Pemahaman Melalui Strategi Probing-Prompting bagi Anak Berkesulitan Belajar - Melly Nadya Afrianti, Marlina Marlina

DOI : https://doi.org/10.31004/basicedu.v5i1.653

sehingga anak yang mengalami kesulitan dalam memahami bacaan merasa tidak diperhatikan sehingga anak jenuh dan bosan dengan apa yang disampaikan (Tambak, 2014). Oleh karena itu anak membutuhkan cara mengajar yang bervariasi agar dapat memahami bacaan dengan baik. Salah satu cara yang dapat digunakan adalah penggunaan strategi probing-prompting.

Strategi probing-prompting adalah strategi yang menyajikan serangkaian pertanyaan dalam proses pembelajaran dengan tujuan untuk menggali dan menuntun siswa aktif dalam proses berpikir ketika mengaitkan pengalaman belajar yang telah didapatkan sebelumnya dengan pengalaman belajar yang akan dipelajari (Marliasari \& Okta, 2018). Strategi probingprompting juga mempunyai keunggulan yang berbeda, salah satu keunggulan tersebut yaitu dapat memberikan kesempatan kepada anak untuk menanyakan hal yang kurang jelas sehingga anak terlihat aktif dan antusias dalam memahami ataupun menjawab pertanyaan, baik pertanyaan lisan maupun tulisan (Muthmainnah, Hapizah, \& Somakim, 2019).

\section{Penggunaan strategi probing-prompting} pada anak berkebutuhan khusus yang berhasil digunakan adalah penelitian (Pennington, Ault, Schuster, \& Sanders, 2011) untuk meningkatkan keterampilan menulis cerita pada tiga orang peserta didik dengan kriteria autis. Hasil dari penelitian dikatakan bahwa keterampilan menulis cerita pada tiga orang peserta didik dengan kriteria autis berhasil ditingkatkan dimana dua dari perserta menunjukkan pemeliharaan dan generalisasi tulisan yang terlatih dan satu peserta dikatakan mengalami peningkatan menulis tanpa adanya bantuan pemeliharaan yang terlatih.

Penggunaan strategi probing-prompting pada anak berkebutuhan khusus juga berhasil digunakan (Vuran, 2008) dalam menguji keefektifan most to least prompting prosedur dalam pembelajaran keterampilan waktu luang praktis untuk orang dewasa kriteria autisme. Kegiatan yang dipilih adalah membuat bentuk keranjang dari tanah liat dan dilaksanakan bersama dua orang dewasa di studio tanah liat di pusat swasta. Hasil dari penelitian menunjukkan metode most to least prompting tidak hanya efektif dalam membuat keranjang dari tanah liat, tetapi juga efektif dalam merawat keterampilan belajar.

\section{METODE}

Jenis penelitian yang digunakan adalah eksperimen dalam bentuk subjek tunggal Singgle Subject Research (SSR). Metode penelitian single subject research merupakan metode yang memiliki tujuan untuk memperoleh data yang diperlukan dengan melihat hasil ada tidaknya pengaruh yang terjadi terhadap suatu perlakuan yang diberikan (Sunanto, 2005). Penelitian ini menggunakan desain A-B-A. Terdapat tiga kondisi yaitu kondisi baseline (A1), kondisi intervensi (B) dan kondisi baseline (A2).

Penelitian ini melibatkan seorang anak perempuan berusia sebelas tahun yang duduk di kelas V SDN 31 Kumpulan Banang. Anak yang bersangkutan merupakan seorang anak yang memiliki kemampuan dalam memahami bacaan yang masih rendah dan tidak sesuai dengan kemampuan memahami bacaan yang seharusnya 
275 Peningkatan Kemampuan Membaca Pemahaman Melalui Strategi Probing-Prompting bagi Anak Berkesulitan Belajar - Melly Nadya Afrianti, Marlina Marlina

DOI : https://doi.org/10.31004/basicedu.v5i1.653

dimiliki oleh anak kelas V SD. Anak sering tertinggal dalam proses pembelajaran, apalagi saat menjawab pertanyaan dan menceritakan kembali apa yang sudah dibaca. Penelitian ini berfokus pada variabel terikat berupa keterampilan membaca pemahaman literal. Sedangkan variabel bebas adalah penggunaan strategi probingprompting.

Pengukuran variabel menggunakan persentase. Teknik pengumpulan data menggunakan teknik tes lisan dan tulisan. Instrumen pengumpulan data adalah instrumen tes membaca pemahaman literal dengan menyuruh anak untuk membaca teks cerita, teks cerita yang diambil adalah teks cerita rakyat, setelah anak selesai membaca teks cerita, anak diberikan lima buah pertanyaan yang menyangkut unsur $5 \mathrm{~W}+1 \mathrm{H}$ (apa, siapa, kapan, dimana dan bagaimana) setelah selesai menjawab pertanyaan anak disuruh untuk menceritakan kembali cerita yang sudah dibaca dengan bahasa sendiri. Teknik analisis data yang digunakan merupakan analisis data visual grafik dalam kondisi dan antar kondisi, yang akan menganalisis komponen berupa tingkat stabilitas, tingkat kecenderungan arah dan tingkat perubahan (level change), dengan membandingkan rata-rata nilai sebelum intervensi dan setelah intervensi.

\section{HASIL DAN PEMBAHASAN}

Pengumpulan data dilakukan sebanyak 17 kali pertemuan dari tanggal 24 Juli- tanggal 05 Agustus 2020, kondisi baseline (A1) dilakukan sebanyak empat pertemuan, kondisi intervensi (B) dilakukan sebanyak tujuh pertemuan dan kondisi baseline (A2) dilakukan sebanyak enam kali.
Strategi probing-prompting diterapkan dengan memberikan masing-masing anak satu lembar teks cerita yang sama, setelah semua anak mendapatkan lembaran teks cerita, peneliti memperintahkan anak satu persatu untuk membaca dengan suara yang lantang, sedangkan peneliti melakukan probing atau menyimak bacaan anak dengan memperhatikan huruf apa yang dihilangkan, diganti dan tambah saat membaca.

Ketika anak sudah selesai membaca, peneliti memberikan lima buah pertanyaan kepada masingmasing anak dalam bentuk tulisan, setelah anak diberikan lima pertanyaan anak disuruh untuk menjawab pertanyaan, setelah menjawab pertanyaan, anak bersama peneliti membahas pertanyaan yang sudah dijawab dengan menunjuk satu anak untuk menjawab pertanyaan, dimana anak yang ditunjuk untuk menjawab pertanyaan itu adalah anak yang mengalami kesulitan membaca pemahaman literal. Jika pertanyaan yang diberikan dijawab dengan benar, guru meminta masukan dari jawaban yang diberikan anak kepada temannya yang tidak bermasalah dalam membaca pemahaman literal. Tetapi jika jawaban yang dijawab salah, guru memberikan pertanyaan baru dengan pertanyaan yang berbeda dengan tujuan yang sama, sehingga anak bisa menjawab pertanyaan awal dengan benar. Jika anak masih tidak bisa menjawab, guru memberikan prompting atau bantuan dengan memancing anak untuk bercerita tetapi tujuan ceritanya menyangkut pertanyaan yang diajukan sebelumnya, sehingga pertanyaan yang diajukan bisa dijawab dengan benar. 
276 Peningkatan Kemampuan Membaca Pemahaman Melalui Strategi Probing-Prompting bagi Anak Berkesulitan Belajar - Melly Nadya Afrianti, Marlina Marlina

DOI : https://doi.org/10.31004/basicedu.v5i1.653

Langkah selanjutnya guru memberikan pertanyaan baru ke semua siswa dengan tujuan untuk memastikan bahwa indikator pada hari itu telah tercapai. Pertanyaan baru tersebut berupa pertanyaan lisan yang disampaikan guru kepada siswa dimana siswa diperintahkan untuk menceritakan kembali cerita yang sudah dibaca dengan bahasa sendiri dalam bentuk tulisan yang bertujuan melihat apakah siswa benar-benar memahami bacaan yang dibaca atau tidak. Data kemudian dianalisis melalui analisis dalam kondisi yang dijelaskan pada grafik berikut :

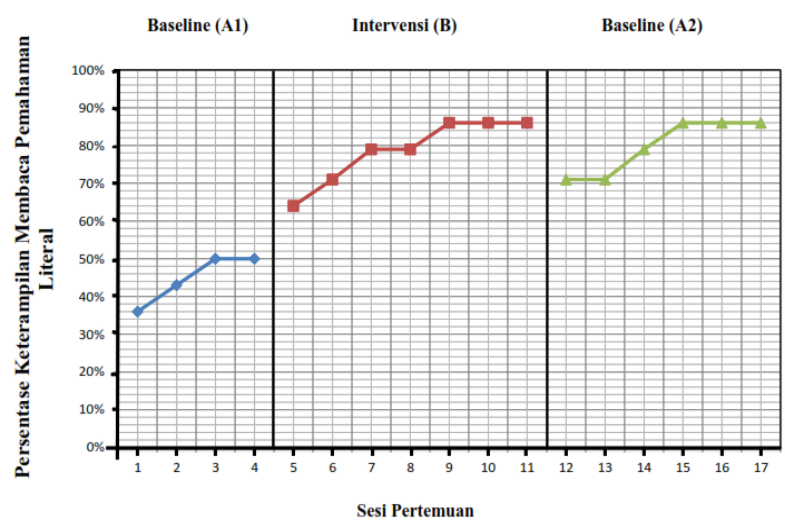

Grafik 1. Analisis dalam Kondisi Membaca Pemahaman

Keterangan:

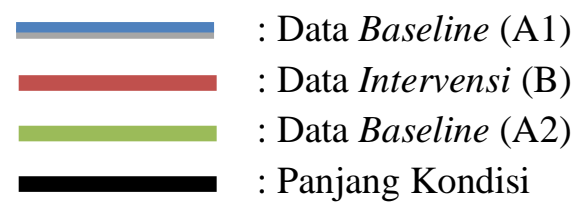

Berdasarkan Grafik 1, analisis dalam kondisi dilihat bahwa pada kondisi baseline (A1) dilakukan empat kali pengamatan didapatkan mean level 44,75, batas atas 48,5 dan batas bawah 41 serta persentase stabilitas yang diperoleh adalah 25\%. Pada kondisi intervensi (B) dilakukan tujuh kali pengamatan didapatkan mean level 78,71, batas atas 85,16 dan batas bawah 72,26 serta persentase stabilitas yang diperoleh adalah 29\%. Pada kondisi baseline (A2) dilakukan enam kali pengamatan didapatkan mean level 79,83, batas atas 86,28 dan batas bawah 73,38 serta persentase stabilitas yang diperoleh adalah $33,33 \%$. Jadi dapat disimpulkan bahwa persentase stabilitas pada kondisi baseline (A1) sebelum diberikan intervensi tidak stabil, kondisi disetelah diberikan intervensi (B) tidak stabil, kondisi baseline (A2) setelah tidak lagi diberikan intervensi juga tidak stabil. Kemudian data dianalisis melalui analisis antar kondisi seperti grafik berikut :

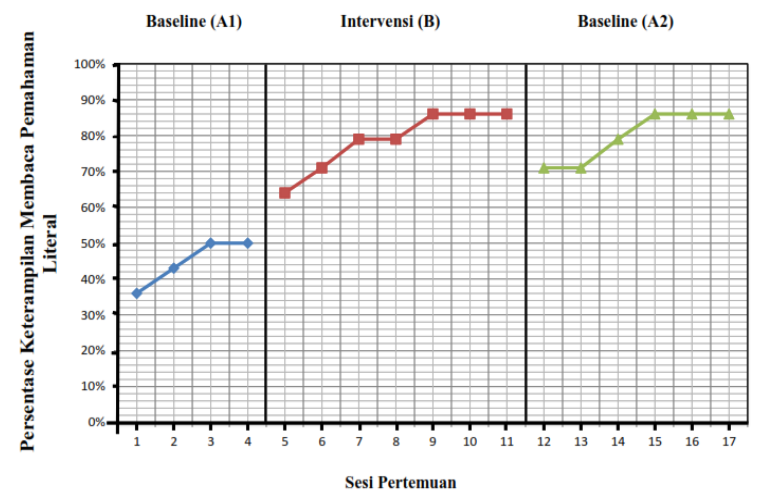

Grafik 2. Analisis Antar Kondisi Membaca Pemahaman

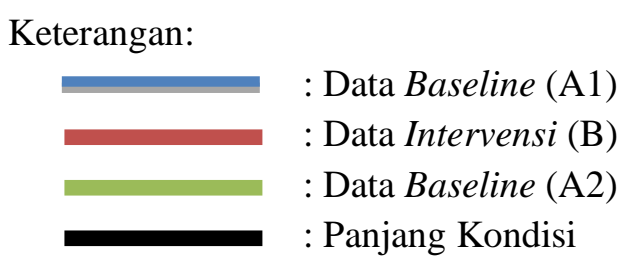

Berdasarkan grafik 2, analisis antar kondisi diatas terlihat panjang kondisi kecenderungan arah pada kondisi baseline A1 mengalami peningkatan $(+)$, untuk kecenderungan arah pada kondisi intervensi B meningkat (+), dan kecenderungan arah pada kondisi baseline (A2) juga mengalami 
277 Peningkatan Kemampuan Membaca Pemahaman Melalui Strategi Probing-Prompting bagi Anak Berkesulitan Belajar - Melly Nadya Afrianti, Marlina Marlina

DOI : https://doi.org/10.31004/basicedu.v5i1.653

peningkatan (+). Sehingga dapat dikatakan bahwa adanya pengaruh positif dari strategi probingprompting terhadap keterampilan membaca pemahaman literal anak berkesulitan belajar.

Kemudian dalam menentuka level perubahan pada masing-masing kondisi maka, data poin terakhir pada kondisi baseline (A1) adalah 50 dan data poin pertama ada kondisi intervensi (B) adalah 36 jadi selisihnya 50-36 = $14(+)$, dan data poin terakhir pada kondisi intervensi (B) adalah 86 data poin pertama pada baseline (A2) adalah 71 jadi selisihnya $86-71=15(+)$ sehingga level perubahan positif (+). Kemudian untuk persentase overlap kondisi intervensi (B) terhadap kondisi baseline (A1) menunjukkan 0\% pada konsisi intervensi (B) dan pada kondisi (A2) 28,57\%. Sehingga semakin kecil persentase overlap yang didapat maka akan semakin baik pula pengaruh intervensi.

Berdasarkan hasil penelitian terbukti bahwa strategi probing-prompting efektif digunakan untuk meningkatkan keterampilan membaca pemahaman literal anak berkesulitan belajar. Proses pembelajaran dengan menggunakan pertanyaan bertujuan untuk menggali kemampuan anak serta membimbing anak untuk lebih aktif.

Langkah awal dalam menerapkan strategi probing-prompting yaitu peneliti terlebih dahulu memberikan teks cerita kepada anak, setelah itu anak disuruh untuk membaca sedangkan peneliti melakukan probing atau menyimak bacaan anak dengan memperhatikan kesalahan-kesalahan yang dilakukan saat membaca. Setelah selesai membaca teks cerita anak diberikan lima pertanyaan dan dijawab pada lembar soal yang telah disediakan, setelah selesai menjawab pertanyaan peneliti dan anak sama-sama membahas jawaban dengan cara peneliti menunjuk anak satu per satu untuk menjawab pertanyaan yang diberikan dan anak yang pertama ditunjuk ditujukan langsung pada anak berkesulitan belajar, jika pertanyaan yang diberikan dijawab dengan benar, guru meminta masukan dari jawaban yang diberikan anak kepada temannya yang tidak bermasalah dalam membaca pemahaman literal. Tetapi jika jawaban yang dijawab salah, guru memberikan pertanyaan baru dengan pertanyaan yang berbeda dengan tujuan yang sama, sehingga anak bisa menjawab pertanyaan awal dengan benar. Jika anak masih tidak bisa menjawab, guru memberikan prompting atau bantuan dengan memancing anak untuk bercerita tetapi tujuan ceritanya menyangkut pertanyaan yang diajukan sebelumnya, sehingga pertanyaan yang diajukan bisa dijawab dengan benar.

Langkah selanjutnya guru memberikan pertanyaan baru ke semua siswa dengan tujuan untuk memastikan bahwa indikator pada hari itu telah tercapai. Pertanyaan baru tersebut berupa pertanyaan lisan yang disampaikan guru kepada siswa dimana siswa diperintahkan untuk menceritakan kembali cerita yang sudah dibaca dengan bahasa sendiri dalam bentuk tulisan yang bertujuan melihat apakah siswa benar-benar memahami bacaan yang dibaca atau tidak.

Pada penelitian ini menunjukkan adanya peningkatan persentase anak kesulitan belajar dalam memahami bacaan. Selama ini keterampilan membaca pemahaman literal anak kesulitan belajar rendah karena kurangnya kreativitas pendidik dalam mengajar. Pendidik selama ini hanya 
278 Peningkatan Kemampuan Membaca Pemahaman Melalui Strategi Probing-Prompting bagi Anak Berkesulitan Belajar - Melly Nadya Afrianti, Marlina Marlina

DOI : https://doi.org/10.31004/basicedu.v5i1.653

menjadi pusat utama dalam pembelajaran, pendidik menyampaikan materi pembelajaran secara langsung kepada anak dengan berbicara panjang lebar tanpa memberikan kesempatan banyak kepada anak untuk bertanya dan mengeluarkan pendapat, pendidik juga selalu mengutamakan anak-anak yang pintar saja sehingga anak yang mengalami kesulitan dalam memahami bacaan merasa tidak diperhatikan sehingga anak jenuh dan bosan dengan apa yang disampaikan.

Penelitian ini relevan dengan penelitian (Swarjawa, Suarjana, \& Garminah, 2013) yang mengatakan bahwa penerapan model pembelajaran probing-prompting berpengaruh baik terhadap hasil belajar IPA dibandingkan dengan penggunakan model pembelajaran konvensional. Strategi probing-prompting juga membuat anak aktif dalam bertanya dan menjawab pertanyaan yang diberikan guru hal itu juga relevan dengan pendapat ahli yang mengatakan bahwa dengan adanya strategi probing-prompting anak bisa dengan aktif mengeksplorasikan pengetahuannya tanpa harus dipaksa (Mustika \& Buana, 2017).

\section{SIMPULAN}

\section{Kesimpulan}

Strategi pembelajaran probing-prompting adalah strategi pembelajaran yang menggunakan pertanyaan-pertanyaan dalam proses belajar yang bertujuan untuk menggali pengetahuan yang dimiliki anak sehingga dalam proses belajar anak lebih aktif. Dari analisis secara keseluruhan, menunjukkan adanya peningkatan dalam membaca pemahaman literal bagi anak berkesulitan belajar.
Maka dari hasil perolehan data dapat dibuktikan bahwa strategi pembelajaran probing-prompting dapat meningkatkan keterampilan membaca pemahaman literal bagi anak berkesulitan belajar kelas V di SDN 31 Kumpulan Banang.

\section{Saran}

Berdasarkan hasil penelitian ini diharapkan kepada semua pihak yang terkait dalam pendidikan anak berkebutuhan khusus, salah satunya anak berkesulitan belajar, untuk dapat memberikan pendidikan yang sesuai dengan kebutuhan dan kondisi anak terutama kepada guru disekolah, agar dapat menerapkan strategi probing-prompting dalam proses belajar mengajar. Sedangkan bagi peneliti selanjutnya, peneliti menyarankan agar dapat mencari ide baru demi pengembangan penelitian ini untuk kedepannya.

\section{DAFTAR PUSTAKA}

Abdullah, R. (2017). Pembelajaran dalam perspektif kreativitas guru dalam pemanfaatan media pembelajaran. Lantanida Journal, 4(1), 35-49.

Abidin, Y. (2012). Model penilaian otentik Dalam pembelajaran membaca pemahaman Beroreintasi pendidikan karakter. Jurnal Pendidikan Karakter, (2).

Khasanah, A., \& Cahyani, I. (2016). Peningkatan kemampuan membaca pemahaman dengan Strategi question answer relationships (qar) Pada Siswa Kelas V Sekolah Dasar. Pedagogik Pendidikan Dasar, 1(2).

Marliasari, S., \& Okta, T. (2018). Teaching Reading Comprehension By Using Probingprompting Learning Strategy To The Eighth Grade Students Of SMPN 7 Palembang. Journal of English Education, Literature and Linguistics, 1(1), 71-88. 
279 Peningkatan Kemampuan Membaca Pemahaman Melalui Strategi Probing-Prompting bagi Anak Berkesulitan Belajar - Melly Nadya Afrianti, Marlina Marlina

DOI : https://doi.org/10.31004/basicedu.v5i1.653

Marlina, M. (2015a). Asesmen Anak Berkebutuhan Khusus: Pendekatan Psikoedukasional Edisi Revisi.

Marlina, M. (2015b). Peer Mediated Intervention for Improving Social Skills of Children with Learning Disabilities in Inclusive Elementary School. Jurnal Pendidikan Humaniora, 2(4), 368-382.

Marlina, M. (2019). Asesmen Kesulitan Belajar. Jakarta: Prenadamedia Group.

Motallebzadeh, K. (2011). Integrating emailing tasks into EFL reading comprehension classrooms. Journal of Language Teaching and Research, 2(4), 881.

Mustika, H., \& Buana, L. (2017). Penerapan Model Pembelajaran Probing Prompting Terhadap Kemampuan Pemecahan Masalah Matematika Siswa. MES: Journal of Mathematics Education and Science, 2(2).

Muthmainnah, M., Hapizah, H., \& Somakim, S. (2019). Penerapan Strategi Probing Prompting Dalam Pembelajaran Matematika Materi Relasi dan Fungsi di SMP. Lentera Sriwijaya: Jurnal Ilmiah Pendidikan Matematika, 1(1), 27-37.

Pennington, R. C., Ault, M. J., Schuster, J. W., \& Sanders, A. (2011). Using Simultaneous Prompting and Computer-Assisted Instruction to Teach Story Writing to Students with Autism. Assistive Technology Outcomes and Benefits, 7(1), 24-38.

Sunanto, J. (2005). Pengantar Pendidikan dengan Subjek Tunggal. Cricet: Universitas Tsukuba.

Swarjawa, I. W. E., Suarjana, M., \& Garminah, N. N. (2013). Pengaruh Model Pembelajaran Probing-Prompting Terhadap Hasil Belajar IPA Siswa Kelas V di SD Negeri 1 Sebatu. MIMBAR PGSD Undiksha, 1(1).

Tambak, S. (2014). Metode Ceramah: Konsep dan Aplikasi dalam Pembelajaran Pendidikan Agama Islam. Jurnal Tarbiyah, 21(2).

Vuran, S. (2008). Empowering Leisure Skills in Adults with Autism: An Experimental Investigation through the Most to Least Prompting Procedure. International Journal of Special Education, 23(1), 174-181. 